\title{
Macroporous nanofibrous vascular scaffold with improved biodegradability and smooth muscle cells infiltration prepared by dual phase separation technique
}

This article was published in the following Dove Press journal:

International Journal of Nanomedicine

\author{
Weizhong Wang' \\ Wei Niel \\ Dinghua Liu' \\ Haibo Du' \\ Xiaojun Zhou' \\ Liang Chen' \\ Hongsheng Wang' \\ Xiumei Mo' \\ Lei $\mathrm{Li}^{2}$ \\ Chuanglong $\mathrm{He}^{\prime}$ \\ 'Key Laboratory of Science \& \\ Technology of Eco-Textiles, \\ Ministry of Education, College of \\ Chemistry, Chemical Engineering and \\ Biotechnology, Donghua University, \\ Shanghai 201620, China; ${ }^{2}$ Department \\ of Gastroenterology, Ninth People's \\ Hospital Affiliated to Shanghai Jiao \\ Tong University School of Medicine, \\ Shanghai $2000 \mathrm{II}$, China
}

Correspondence: Chuanglong $\mathrm{He}$ Key Laboratory of Science \& Technology of Eco-Textiles, Ministry of Education, College of Chemistry, Chemical Engineering and Biotechnology, Donghua University, 2999 North Renmin Road, Shanghai 201620, China

Tel/fax+86 2l 67792742

Email hcl@dhu.edu.cn

Lei Li

Department of Gastroenterology, Ninth People's Hospital Affiliated to Shanghai Jiao Tong University School of Medicine, 639 Zhizaoju Road, Shanghai 2000 II, China

Email lilei2968900@।63.com
Introduction: The fast degradation of vascular graft and the infiltration of smooth muscle cells (SMCs) into the vascular graft are considered to be critical for the regeneration of functional neo-vessels. In our previous study, a novel dual phase separation technique was developed to one-pot prepare macroporous nanofibrous poly(L-lactic acid) (PLLA)/poly( $\varepsilon$-caprolactone) (PCL) vascular scaffold by phase separating the immiscible polymer blend. However, the slow degradation of PLLA/PCL limited cell infiltration. Herein, we hypothesized that poly(lactic-coglycolic acid) (PLGA) would be miscible with PLLA but immiscible with PCL. Then, PLGA can be introduced into the PLLA/PCL blend to fabricate macroporous nanofibrous scaffold with improved biodegradability by using dual phase separation technique.

Materials and methods: The miscibility of PLGA with PLLA and PCL was evaluated. Then, the PLLA/PLGA/PCL scaffold was prepared by dual phase separation technique. The prepared scaffolds were characterized in terms of the morphology, in vitro degradation, mechanical properties, and cells' infiltration and viability for human vascular SMCs (HVSMCs). Finally, platelet-derived growth factor-BB (PDGF-BB) was immobilized on the scaffold and its effect on the bioactivity of HVSMCs was studied.

Results: PLGA is miscible with PLLA but immiscible with PCL as hypothesized. The addition of PLGA enlarged the pore size and improved the biodegradability of composite scaffold. Notably, PLLA/PLGA/PCL scaffold with the blend ratio of 30:40:30 possessed improved pore interconnectivity for cells' infiltration and enough mechanical properties. Moreover, HVSMCs could grow and infiltrate into this scaffold, and surface modification with PDGF-BB on the nanofibrous scaffold enhanced HVSMCs migration and proliferation.

Conclusion: This study provides a strategy to expand dual phase separation technique into utilizing ternary even multinary polymer blend to fabricate macroporous nanofibrous scaffold with improved physicochemical properties. The prepared PLLA/PLGA/PCL scaffold would be promising for the regeneration of functional tunica media in vascular tissue engineering.

Keywords: immiscible polymer blend, porous, nanofibrous, vascular scaffold, PDGF-BB

\section{Introduction}

Scaffold is a critical factor in tissue engineering. It serves as the temporary extracellular matrix (ECM) for cell attachment, proliferation, differentiation, and tissue regeneration. ${ }^{1}$ Ideal scaffold was commonly designed to be highly porous for cell infiltration, nutrients and oxygen transport, and metabolic waste removal, thereby facilitating the regeneration of functional neotissues..$^{2-4}$ For instance, the vascular graft was often designed 
to be porous for enabling the infiltration of vascular smooth muscle cells (SMCs) and regeneration of functional tunica media, ${ }^{5}$ thereby endowing the neo-vessel with the contractile function. Moreover, nanofibrous structure resembling native ECM is another important feature that can provide a biomimetic microenvironment for enhanced cell attachment, proliferation, and differentiation. ${ }^{6-8}$

In our previous study, ${ }^{9}$ we have developed a novel and facile dual phase separation technique to one-pot prepare macroporous and nanofibrous poly(L-lactic acid) (PLLA)/ poly( $\varepsilon$-caprolactone) (PCL) scaffold by phase separating the immiscible binary polymer blend solution of PLLA/PCL. However, the as-prepared PLLA/PCL composite scaffold degraded very slowly due to the inherent slow degradation rate of PLLA and PCL. ${ }^{10,11}$ It usually takes at least 1 year for their complete degradation in vitro even in vivo, ${ }^{12,13}$ which cannot match the growth rate of most tissues or organs in human body. Wang et al reported that the vascular graft prepared from a fast degradable polymer, poly(glycerol sebacate) (PGS), enabled the successful regeneration of functional neoartery within 3 months. ${ }^{14}$ They claimed that fast degradation of tissue engineering scaffold could enable the rapid host remodeling of diseased or damaged tissues.

Poly(lactic-co-glycolic acid) (PLGA) is a synthetic copolymer of lactic acid and glycolic acid, which has been widely used in tissue engineering and drug delivery applications due to its excellent biocompatibility and biodegradability. ${ }^{15,16}$ It usually degrades more rapidly than PLLA and PCL. ${ }^{17}$ Also, it has the similar structural component with another synthetic elastic copolymer poly(L-lactide-co- $\varepsilon$-caprolactone) (PLCL), which is miscible with PLLA. ${ }^{18}$ Interestingly, the addition of PLCL into the phase separation system of PLLA could not affect the microstructure of composite scaffold but significantly improved its elasticity. ${ }^{19}$ Hence, we hypothesized that PLGA would be miscible with PLLA as PLCL but immiscible with PCL. Based on this hypothesis and the mechanism of dual phase separation technique developed in our previous study, ${ }^{9}$ the ternary PLLA/PLGA/PCL solution could be separated into two phases, the polymer solution containing PLLA and PLGA with high mass fraction would serve as the continuous phase due to the mutual miscibility of PLLA and PLGA, but PCL solution with low mass fraction would serve as pore-forming phase due to its immiscibility with PLLA and PLGA (macro-phase separation) (Scheme 1). Afterward, the continuous phase containing PLLA and PLGA could gel at a low temperature and further separate into polymer-rich phase and polymer-lean phase (nanophase separation), while the pore-forming phase consisting of PCL cannot gel at the low temperature and still exists in the polymer gel by the form of liquid droplets. After solvent exchanging by water, the continuous phase could be formed into nanofibrous network, but liquid pore-forming phase could be scoured by water, resulting in the formation of spherical macropores. Therefore, such dual phase separation technique can be expanded into using ternary polymer blend to prepare macroporous nanofibrous scaffold with improved biodegradability by introducing PLGA into the PLLA/PCL blend.

The purpose of this study was to fabricate a macroporous nanofibrous scaffold with improved biodegradability and cells' infiltration. Hence, we first verified our hypothesis about the miscibility of PLGA with PLLA and PCL. Then, the ternary polymer blend of PLLA/PLGA/PCL was used to prepare composite scaffolds by using dual phase separation technique. The microstructure, degradation behavior, and mechanical properties of the resulting scaffolds were

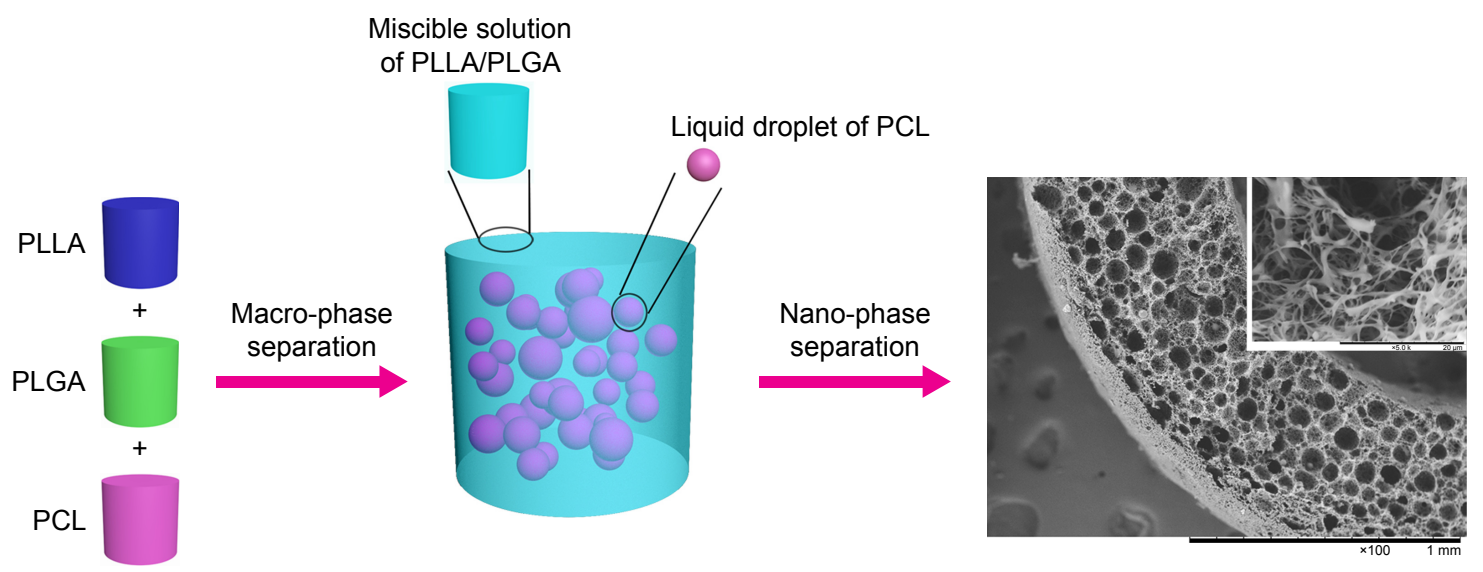

Scheme I Schematic illustration of dual phase separating PLLA/PLGA/PCL blend to fabricate macroporous and nanofibrous scaffold. Abbreviations: PCL, poly( $\varepsilon$-caprolactone); PLGA, poly(lactic-co-glycolic acid); PLLA, poly(L-lactic acid). 
evaluated. Next, the PLLA/PLGA/PCL scaffolds were subcutaneous implanted in Sprague Dawley (SD) rats to assess the pore interconnectivity and pore size of composite scaffold for cell infiltration. In order to further evaluate the potential application of the porous scaffold in the reconstruction of tunica media in vascular tissue engineering, human vascular SMCs (HVSMCs) were seeded on the as-prepared PLLA/PLGA/PCL composite scaffold to evaluate HVSMCs' proliferation and infiltration ability. Finally, platelet-derived growth factor-BB (PDGF-BB), a bioactive factor that can cause SMCs to proliferate and migrate, ${ }^{20}$ was immobilized on the surface of PLLA/PLGA/PCL scaffolds to enhance the interactions of SMCs with the nanofibrous scaffolds, including cells' proliferation and migration.

\section{Materials and methods Materials}

PLLA (1.93 dL/g inherent viscosity) and PLGA (50:50, $0.46 \mathrm{dL} / \mathrm{g}$ inherent viscosity) were obtained from Daigang Biomaterials Inc. (Jinan, China). PCL (Mn: 80,000), tetrahydrofuran (THF), sodium azide $\left(\mathrm{NaN}_{3}\right)$, and $\mathrm{H} \& \mathrm{E}$ were purchased from Sigma-Aldrich Co. (St Louis, MO, USA). Masson stain kit was purchased from Nanjing Jiancheng Bioengineering Institute (Nanjing, China). 2-(N-Morpholino) ethanesulfonic acid, $\mathrm{N}$-(3dimethylaminopropyl)- $N$ '-ethylcarbodiimide hydrochloride (EDC), $N$-hydroxysuccinimide (NHS), and heparin sodium salt (185 USP unit/mg) were purchased from Aladdin Industrial Corporation (Shanghai, China). PBS powder ( $\mathrm{pH} 7.2$ 7.4) was obtained from Solarbio Life Sciences Inc. (Beijing, China). DAPI was purchased from Bestbio (Shanghai, China). FBS and DMEM were obtained from Thermo Fisher Scientific (Waltham, MA, USA). Trypsin, penicillin (100 U/mL), and streptomycin $(100 \mu \mathrm{g} / \mathrm{mL})$ were purchased from Shanghai Yuanxiang Medical Equipment Co., Ltd (Shanghai, China). Recombinant human PDGF-BB and human PDGF-BB ELISA development kit were purchased from Peprotech (Rocky Hill, CT, USA). Di-amino-poly(ethylene glycol) (di$\mathrm{NH}_{2}$-PEG) was purchased from Yarebio Co., Ltd (Shanghai, China). Cell counting kit-8 (CCK-8), BSA, and Triton X-100 were obtained from Beyotime Institute of Biotechnology (Shanghai, China). Calcein-AM was purchased from Yeasen Biotechnology Co., Ltd (Shanghai, China).

\section{Fabrication of PLLA/PLGA/PCL scaffolds} PLLA/PLGA/PCL composite scaffolds were fabricated by using dual phase separation technique. Briefly, PLLA/PLGA/ PCL blends with various weight ratios (70:0:30, 60:10:30,
50:20:30, 40:30:30, and 30:40:30) were first dissolved in $\mathrm{THF}$ at $60^{\circ} \mathrm{C}$ under magnetic stirring to obtain homogeneous solutions $(10 \%, \mathrm{w} / \mathrm{v})$. Then, the polymer blend solutions were immediately casted into preheated $\left(60^{\circ} \mathrm{C}\right)$ Teflon molds and placed in $-80^{\circ} \mathrm{C}$ ultralow temperature refrigerator for at least 12 hours. After that, the polymer gels were obtained and then taken out from the molds and immersed into an ice/water mixture to exchange THF for 48 hours, changing the ice/water mixture three times per 24 hours. Finally, the scaffolds were obtained by freeze-drying for 2 days.

\section{Morphological characterization}

Before characterization, the composite scaffolds were fractured after being frozen in liquid nitrogen for several minutes. The samples were sputter coated with gold using a sputter coater and then observed by using a scanning electron microscope (SEM; TM-1000; Hitachi Ltd., Tokyo, Japan) at $10 \mathrm{kV}$. The average pore diameter (AD) of samples was obtained from at least 80 measurements on at least two typical SEM images using the Image J 1.40G software (National Institutes of Health, Bethesda, MD, USA), and the average fiber diameter of samples was obtained from at least 80 measurements on a typical SEM image using the ImageJ $1.40 \mathrm{G}$ software.

\section{In vitro degradation}

In vitro degradation test was conducted according to our previous study. ${ }^{21}$ Briefly, the samples with initial dry weights were first wetted and then immersed in $15 \mathrm{~mL}$ centrifugal tubes containing $5 \mathrm{~mL}$ of PBS solution $(\mathrm{pH} 7.03)$ and $0.02 \%(\mathrm{w} / \mathrm{v}) \mathrm{NaN}_{3}$. The tubes were placed in an orbital incubator with the rotational speed of $100 \mathrm{rpm}$ at $37^{\circ} \mathrm{C}$ for up to 11 weeks. At the predetermined intervals, the samples were taken out from the tubes and weighed $(\mathrm{Wd})$ after freeze-dried. The $\mathrm{pH}$ of the degradation solution was measured using a pH meter (PHS-3C; Rex, Shanghai, China). The mass loss of samples was calculated by

$$
\text { Weight loss }(\%)=\frac{\mathrm{Wo}-\mathrm{Wd}}{\mathrm{Wo}} \times 100 \%
$$

The values were expressed as mean $\pm \operatorname{SD}(n=3)$.

\section{Mechanical measurement}

The tensile testing and compressive testing of samples were performed using a universal material tester (H5K-S; Hounsfield, Redhill, UK) at room temperature according to our previous study. ${ }^{19}$ The samples for tensile testing were prepared by using the same method as described earlier 
except utilizing a new circular PTFE mold with a diameter of $70 \mathrm{~mm}$ and a thickness of $1 \mathrm{~mm}$ and cut into strips with a dimension of $50 \times 10 \mathrm{~mm}$. Before testing, the thickness of samples was measured using a micrometer. A cross-head speed for tensile testing was $10 \mathrm{~mm} / \mathrm{min}$, and the gage length was $30 \mathrm{~mm}$. The samples for compressive testing were fabricated into cylinders with the diameter of about $14 \mathrm{~mm}$ and the height of about $10 \mathrm{~mm}$ by using cylindrical PTFE mold. A cross-head speed of $1 \mathrm{~mm} / \mathrm{min}$ was used for compressive testing. At least five specimens were tested for each sample. The suture strength of PLLA/PLGA/PCL 30:40:30 tubular scaffold $(n=4)$ was measured according to a previous report. ${ }^{22}$ Briefly, one end of the tubular scaffold was fixed to the stage clamp of the test machine. The other end was sutured with an $8-0$ prolene suture at $2 \mathrm{~mm}$ from the edge of tubular scaffold, and then, the suture was connected with another clamp. Afterward, the test was performed with a cross-head speed of $10 \mathrm{~mm} / \mathrm{min}$ until the scaffold fractured. The fractured strength was recorded as the suture strength.

\section{Heparin conjugation and PDGF-BB immobilization}

Heparin was conjugated on the surface of PLLA/PLGA/ PCL scaffold by using EDC/NHS chemistry with di- $\mathrm{NH}_{2}-$ PEG as a linker. ${ }^{23}$ Briefly, the scaffolds were first immersed into sodium hydroxide $(\mathrm{NaOH})$ solution $(0.01 \mathrm{~N})$ for about 10 minutes to activate the carboxylic groups on the surface of scaffold, followed by washing three times with distilled water. di- $\mathrm{NH}_{2}-\mathrm{PEG}$ was then covalently attached to the scaffolds by immersing the activated scaffolds in freshly prepared MES buffer solution ( $\mathrm{pH} 5.5$ ) containing $1 \mathrm{mg} / \mathrm{mL}$ of di-NH $\mathrm{N}_{2}$-PEG, 0.5 M NaCl, 0.06 M NHS, and 0.12 M EDC for 16 hours at room temperature. After washing for three times with distilled water, the aminated scaffolds were immersed in another freshly prepared MES buffer solution ( $\mathrm{pH} 5.5$ ) containing $1 \mathrm{mg} / \mathrm{mL}$ of heparin sodium, $0.5 \mathrm{M} \mathrm{NaCl}, 0.06 \mathrm{M}$ NHS, and 0.12 M EDC for 24 hours at room temperature. The obtained scaffolds (PLLA/PLGA/PCL-Heparin scaffolds) was then washed three times with distilled water and freeze-dried for further use.

The heparinized circular scaffolds with the diameter of $10 \mathrm{~mm}$ were utilized to immobilize growth factor PDGF-BB. Briefly, the heparinized scaffolds were placed in the wells of 48 -well plate. Then, $100 \mu \mathrm{L}$ of PDGF-BB solution $(1 \mu \mathrm{g} / \mathrm{mL}$ in PBS) was added into each well and incubated at $4^{\circ} \mathrm{C}$ for 8 hours. After immobilization, the resulting scaffolds (PLLA/ PLGA/PCL-PDGF-BB scaffolds) were washed with PBS to remove unbonded growth factor. In order to quantify the loading amount of PDGF-BB on the scaffolds, the remaining supernatant after immobilization and the washing solution were collected and used to measure the concentration of PDGF-BB by using the ELISA kit.

\section{In vitro cell culture}

HVSMCs were purchased from Shanghai Yanjing Biotech Co., Ltd (Shanghai, China) and cultured in DMEM supplemented with $10 \% \mathrm{FBS}, 100 \mathrm{U} / \mathrm{mL}$ of penicillin, and $100 \mu \mathrm{g} / \mathrm{mL}$ of streptomycin at humid atmosphere, $5 \% \mathrm{CO}_{2}$, and $37^{\circ} \mathrm{C}$. In order to evaluate HVSMCs' proliferation on the PLLA/PLGA/PCL scaffold, the sterile circular specimens $(n=4)$ were placed into 24 -well culture plates and washed twice with cell culture medium for 1 hour each. HVSMCs were then seeded at the density of $1.0 \times 10^{5}$ cells/well on the PLLA/PLGA/PCL scaffolds and cultured for 1, 4, and 7 days, changing the medium every other day. PLLA/PCL scaffolds were served as controls. At the predetermined intervals, the seeded scaffolds were washed three times with sterile PBS and, then, $360 \mu \mathrm{L}$ of DMEM and $40 \mu \mathrm{L}$ of CCK-8 reagent were added per well. After placing in the incubator at $37^{\circ} \mathrm{C}$ with $5 \% \mathrm{CO}_{2}$ for 30 minutes, $100 \mu \mathrm{L}$ of reaction solution was transferred into 96-well culture plate and measured at $450 \mathrm{~nm}$ using the microplate reader (Multiskan GO; Thermo Fisher Scientific). Actually, the CCK-8 solution has an original absorbance value due to its own red color. Hence, the difference absorbance value for the scaffold with and without seeding cells was calculated to reflect the true number of cells on the scaffold.

In order to evaluate the infiltration of SMCs into the PLLA/PLGA/PCL scaffolds, HVSMCs were seeded at the density of $5.0 \times 10^{5}$ cells/well on the scaffolds and cultured for 7 days. After that, the cell-seeded scaffolds were washed with PBS and then soaked in paraformaldehyde for 30 minutes to fix HVSMCs. After that, the cell-seeded scaffolds were dehydrated through a graded series of ethanol and embedded with paraffin. The samples were cross-sectioned at a thickness of $4 \mu \mathrm{m}$ and stained with H\&E. In addition, $\alpha$-smooth muscle actin ( $\alpha$-SMA) was identified by immunofluorescence staining with mouse monoclonal anti- $\alpha$-SMA antibody (1:500; Servicebio, Wuhan, China) as primary antibody and Cy3-conjugated goat anti-mouse IgG (1:300; Servicebio) as secondary antibody. The cell nucleus was stained by DAPI.

In order to estimate the effect of surface modification in scaffold on the proliferation of HVSMCs, the sterile PLLA/PLGA/PCL-Heparin scaffolds and PLLA/PLGA/ PCL-PDGF-BB scaffolds $(n=4)$ were placed into 48-well 
culture plates. HVSMCs were then seeded at the density of $5.0 \times 10^{4}$ cells/well and cultured for 1,4 , and 7 days. The untreated PLLA/PLGA/PCL scaffolds were served as controls. At the predetermined intervals, the viability of cells on the scaffolds was measured by using the CCK- 8 assay. Briefly, the seeded scaffolds were washed with sterile PBS for three times and, then, $300 \mu \mathrm{L}$ of CCK-8 working solution was added per well and cultured in the cell incubator for 1 hour. Subsequently, $100 \mu \mathrm{L}$ of reaction solution was transferred into 96-well culture plate and measured at $450 \mathrm{~nm}$ using a microplate reader.

For the staining of living cells, the cells cultured on the samples were washed with sterile PBS, then stained by Calcein-AM solution for 10 minutes at room temperature, and observed by a microscope (IX71; Olympus Corporation, Tokyo, Japan).

\section{HVSMCs' migration assay}

The migration of HVSMCs was evaluated by using a Transwell system (8 $\mu \mathrm{m}$ pores, Costar 3422) ${ }^{24}$ Briefly, the sterile samples (PLLA/PLGA/PCL scaffold, PLLA/PLGA/ PCL-Heparin scaffold, and PLLA/PLGA/PCL-PDGF-BB scaffold, $n=3$ for each sample) were first placed in the lower chamber and then coated with $600 \mu \mathrm{L}$ of serum-free DMEM for about 24 hours at $37^{\circ} \mathrm{C}$. The blank lower chamber without any scaffolds was served as the control. Next, $200 \mu \mathrm{L}$ of serum-free DMEM containing $2.0 \times 10^{4} \mathrm{HVSMCs}$ was added on the upper chamber. After culturing in the cell incubator for another 24 hours, the cells on the upper surface of the Transwell membrane were scraped by a cotton tip applicator. Then, the migratory cells on the lower surface of the membrane were fixed by using 4\% paraformaldehyde for 30 minutes. After washing with PBS, the fixed cells were stained using $600 \mu \mathrm{L}$ of $25 \%$ crystal violet for 30 minutes. The stained cells were then photographed with microscope (IX71). To quantify the migratory cells, $400 \mu \mathrm{L}$ of $10 \%$ acetic acid was used to elute the crystal violet in the migratory cells and then measured at $590 \mathrm{~nm}$ using a microplate reader (Multiskan GO).

\section{In vivo subcutaneous implantation}

Animals care and treatment were conducted in accordance with the Institutional Animal Care and Use Committees (IACUC) guidelines of Ninth People's Hospital Affiliated to Shanghai Jiao Tong University School of Medicine. The protocol was approved by the Animal Care and Experiment Committee of Ninth People's Hospital Affiliated to Shanghai Jiao Tong University School of Medicine. The tubular
PLLA/PLGA/PCL 30:40:30 scaffolds were implanted into subcutaneous pockets of SD rats (male, 3 months old). At predetermined periods $(1,2,4$, and 8 weeks), the implants were harvested from SD rats and fixed with $10 \%$ formaldehyde in PBS overnight. Then, the fixed implants were dehydrated through a graded series of ethanol, embedded in paraffin, and sectioned at a thickness of $4 \mu \mathrm{m}$. Finally, the sections were deparaffinized, rehydrated with a graded series of ethanol, stained with H\&E and Masson Stain Kit, and observed by a microscope (IX71).

\section{Statistical analysis}

Experimental data were reported as mean \pm SD. Statistical analysis was carried out by one-way ANOVA using Tukey's post hoc analysis. Statistical significance was represented as $* P<0.05$ and $* * P<0.01$.

\section{Results and discussion Theoretical analysis}

In this study, the hypothesis about the miscibility of PLGA with PLLA and PCL was first evaluated. As we know, PLLA, PLGA, and PCL can dissolve in THF to obtain a homogeneous and clear solution because THF is the solvent for them. As a result, the blend solution of PLLA/PLGA is still clear (Figure 1A), meaning that PLGA is miscible with PLLA and no phase separation occurs in the mixture solution at $60^{\circ} \mathrm{C} .^{25}$ That is also reflected in the microstructure of the prepared PLLA/PLGA composite scaffold shown in Figure 1B. It shows nanofibrous structure without spherical macropores in the scaffold. However, the blend solution of PCL/PLGA becomes turbid, meaning that PLGA is immiscible with PCL and phase separation occurs in this mixture solution. No PCL/PLGA composite scaffold is prepared by using thermally induced phase separation (TIPS) technique because PCL/PLGA mixture solution cannot gel at low temperature. The above results confirmed our hypotheses about the miscibility of PLGA with PLLA and PCL and the mechanism of dual phase separating ternary PLLA/PLGA/ PCL solution (Scheme 1) that provides a theoretical support for fabricating macroporous and nanofibrous scaffold with improved biodegradability by dual phase separating ternary polymer blend solution of PLLA/PLGA/PCL.

\section{Morphological characterization}

As reported in our previous study, ${ }^{9}$ PLLA/PCL composite scaffold possessed optimal porous structure when the PCL content reached to $30 \%$. Hence, in order to maintain the proper porous structure of the composite scaffold when PLGA is introduced 
A

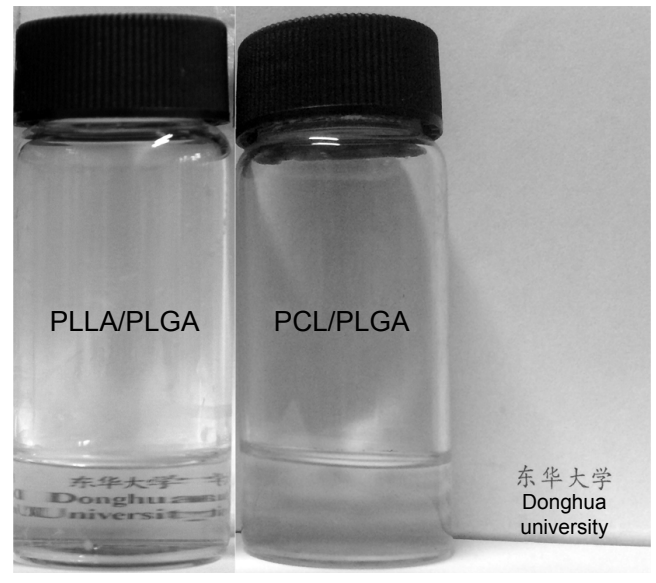

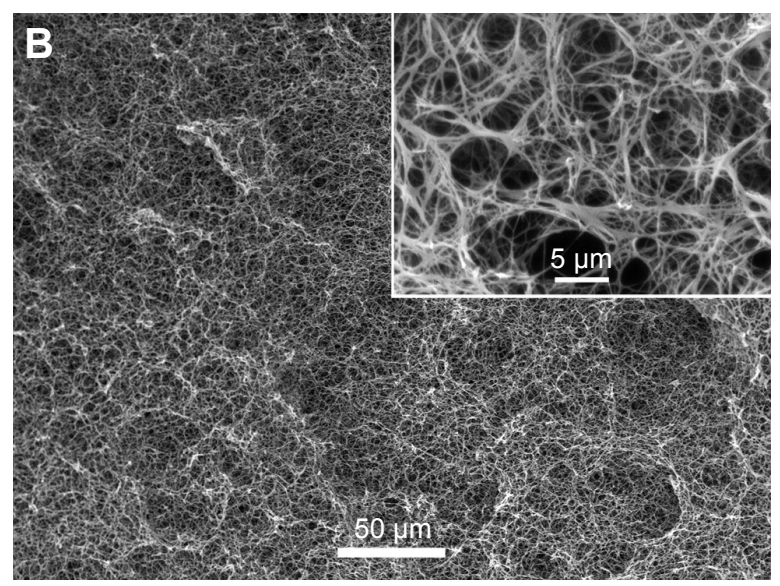

Figure I (A) The clarity situation of polymer blends of PLLA/PLGA and PCL/PLGA dissolved in THF with $10 \%$ (w/v) concentration at $60^{\circ} \mathrm{C}$. The blend solution of PLLA/PLGA is clear, meaning the miscibility of PLLA and PLGA, while the blend solution of PCL/PLGA is turbid, indicating that PLGA is immiscible with PCL. (B) The SEM images of scaffold prepared from polymer blend of PLLA/PLGA.

Abbreviations: PCL, poly(E-caprolactone); PLGA, poly(lactic-co-glycolic acid); PLLA, poly(L-lactic acid); SEM, scanning electron microscope; THF, tetrahydrofuran.

into the PLLA/PCL blend, PCL content in this ternary polymer blend is held constant at $30 \%$ in this study. Then, the effect of adding PLGA on the microstructure of the composite scaffold was studied. As shown in Figure 2 and the pore diameter distribution data of PLLA/PCL 70:30 scaffold reported in our previous study, ${ }^{9}$ all PLLA/PLGA/PCL scaffolds show spherical macroporous and nanofibrous structure and the $\mathrm{AD}$ is basically increased from $38.4 \pm 19.3$ to $76.2 \pm 38.8 \mu \mathrm{m}$ as PLGA content increases from 0 to $40 \%$. These pores with the size of greater than $10 \mu \mathrm{m}$ are deemed to be large enough for cells' infiltration. ${ }^{26}$ The introduction of PLGA also results in the formation of larger size pores $(>120 \mu \mathrm{m})$, broadening the range of pore size distribution in the scaffolds. Notably, PLLA/PLGA/PCL scaffold with the blend ratio of 30:40:30 shows better pore interconnectivity than the scaffolds made from other blend ratios (Figure 2). However, it is hard to obtain intact tubular composite scaffold when PLGA content further increases, because PLGA cannot gel at low temperature. The average fiber diameter of all PLLA/PLGA/PCL scaffolds is slightly larger than PLLA/PCL scaffold (Figure 3). It may be due to that PLGA does not form nanofibers by using TIPS. While there is no significantly difference in fiber diameter among different PLLA/PLGA/PCL composite scaffolds. Their average fiber diameters are about $450 \mathrm{~nm}$, resembling the size of collagen fibers in natural ECM. ${ }^{27}$

\section{In vitro degradation}

In order to investigate the effect of PLGA on the degradation behavior of PLLA/PLGA/PCL composite scaffolds, the weight loss of scaffolds after immersing in PBS and the $\mathrm{pH}$ value of degradation solutions were measured and are shown in Figure 4. As shown in the figure, the degradation ratio increases with the PLGA content in scaffolds, while there is almost no weight loss for PLLA/PCL scaffold in this degradation test. After degradation for more than 7 weeks, the weight loss of scaffolds tends to close to the value of PLGA content in each scaffold. These results indicate that the degradation of PLLA/PLGA/PCL scaffolds is mainly tuned by the PLGA component. In addition, the degradation of PLGA induces the decrease in $\mathrm{pH}$ value of the degradation solutions (Figure 4B), which is mainly due to the production of acid degradation products.

The microstructure of composite scaffold after degradation in vitro was also observed. As shown in Figure 5, after degradation for up to 8 weeks, there is no obvious change in the microstructure of composite scaffolds when the PLGA content is less than $40 \%$, but improved pore interconnectivity and much smoother macropore surface were observed in PLLA/PLGA/PCL 30:40:30 scaffold after degradation for 8 weeks (Figure 6). In fact, these changes in microstructure in PLLA/PLGA/PCL 30:40:30 scaffold occurred just after degradation for 1 week. The surface of pore walls becomes much smoother after degradation, and the pore interconnectivity is also improved along with the degradation time. The average pore size of PLLA/PLGA/PCL 30:40:30 scaffolds does not vary with the degradation time, while the nanofibers within the scaffold are partly eroded after degradation (Figure 6). The above results show the stepwise degradation property of PLLA/PLGA/PCL 30:40:30 scaffold. The fast degradation of PLGA improves the pore interconnectivity and enables cells' infiltration, while the slow degradation of residual porous PLLA/PCL frame provides the three-dimensional (3D) space 

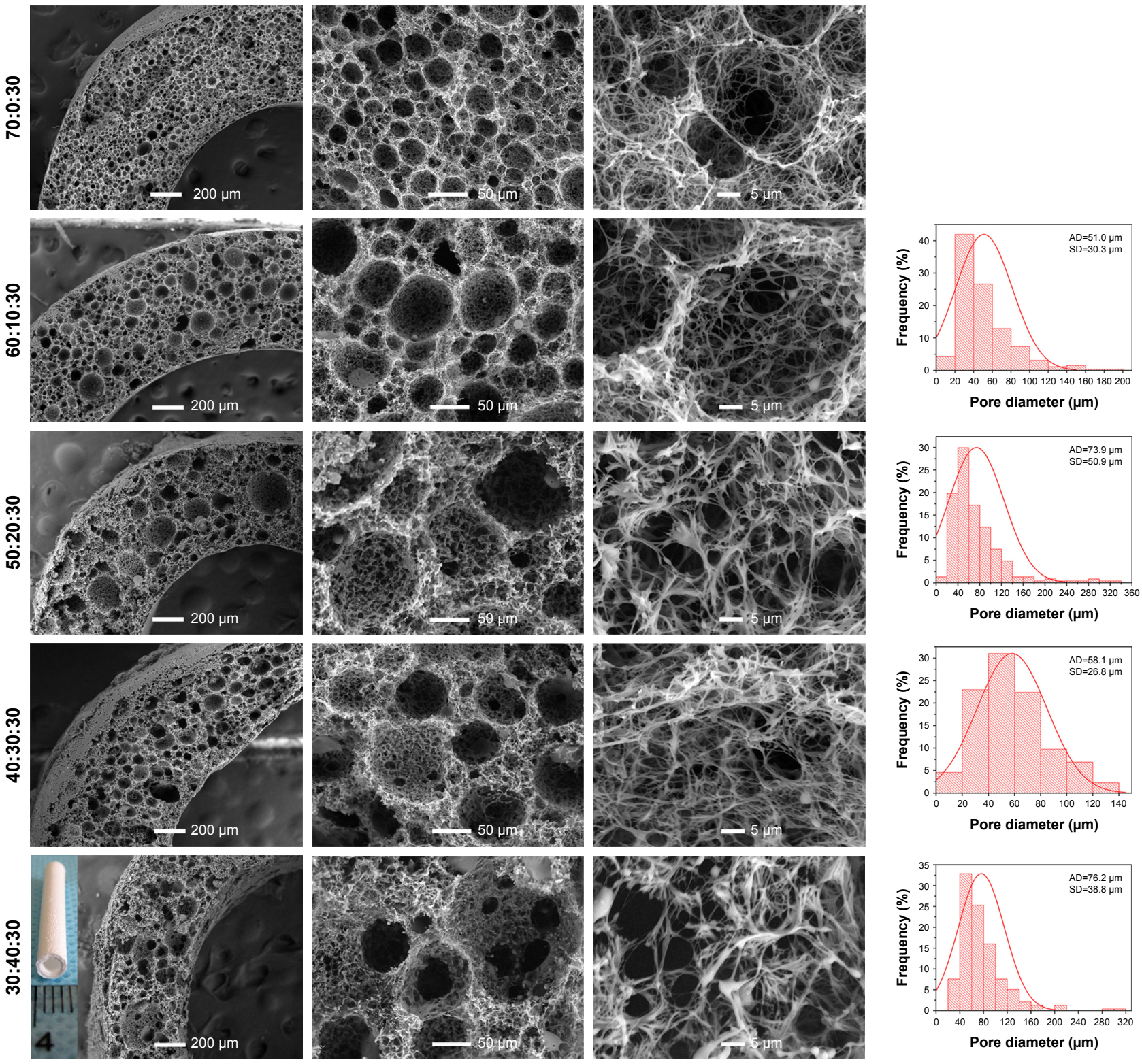

Figure 2 The SEM images and pore diameter distributions of PLLA/PLGA/PCL composite scaffolds with various weight ratios.

Note: The inset image was the macroscopic picture of PLLA/PLGA/PCL 30:40:30 tubular scaffold.

Abbreviations: AD, average pore diameter; PCL, poly(E-caprolactone); PLGA, poly(lactic-co-glycolic acid); PLLA, poly(L-lactic acid); SEM, scanning electron microscope.

for subsequent tissue remodeling. Hence, PLLA/PLGA/PCL 30:40:30 scaffold was selected for further studies.

\section{Mechanical properties}

Then, the tensile and compressive mechanical properties of the composite scaffold were investigated, because the mechanical properties of tissue engineering scaffold are important to maintain structural stability to withstand stress when it is cultured in vitro or implanted in vivo. ${ }^{28}$ Figure 7 shows the tensile mechanical properties of the composite scaffold. As shown in Figure 7A, the two scaffolds display a nonlinear stress-strain response under tensile loading. The ultimate strain and tensile strength of PLLA/PLGA/PCL scaffold are only $4.6 \% \pm 1.0 \%$ and $0.18 \pm 0.04 \mathrm{MPa}$, respectively, which are significantly less than those of PLLA/PCL scaffold (Figure 7B and C). However, the elastic modulus of PLLA/PLGA/PCL scaffold is slightly more than that of PLLA/PCL scaffold (Figure 7D). The tensile properties of PLLA/PLGA/PCL scaffold after degradation in vitro for 5 weeks were also investigated, but the strip samples after degradation were too fragile to be measured under tensile loading (data not shown). Notably, the tensile properties of 


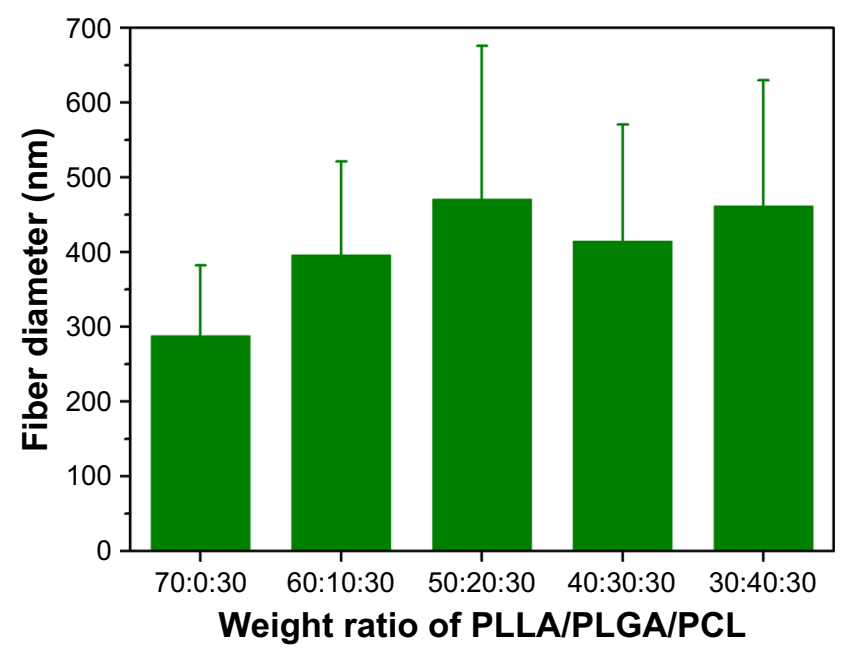

Figure 3 The fiber diameter of PLLA/PLGA/PCL composite scaffolds with various weight ratios.

Abbreviations: PCL, poly(E-caprolactone); PLGA, poly(lactic-co-glycolic acid); PLLA, poly(L-lactic acid).

the PLLA/PLGA/PCL scaffold were significantly weaker than those of native coronary arteries, which possessed the tensile strength of 1.40-11.14 MPa and the ultimate strain of $45 \%-99 \%{ }^{29}$ In addition, Figure 8 shows the compressive properties of PLLA/PCL scaffold and PLLA/PLGA/PCL scaffold before and after degradation in vitro for 5 weeks. Figure 8A shows the typical compressive stress-strain curves of samples at the range of $30 \%$ strain, because all the samples cannot collapse under compressive loading. The curves at the strain more than $30 \%$ cannot reflect the real compressive

A

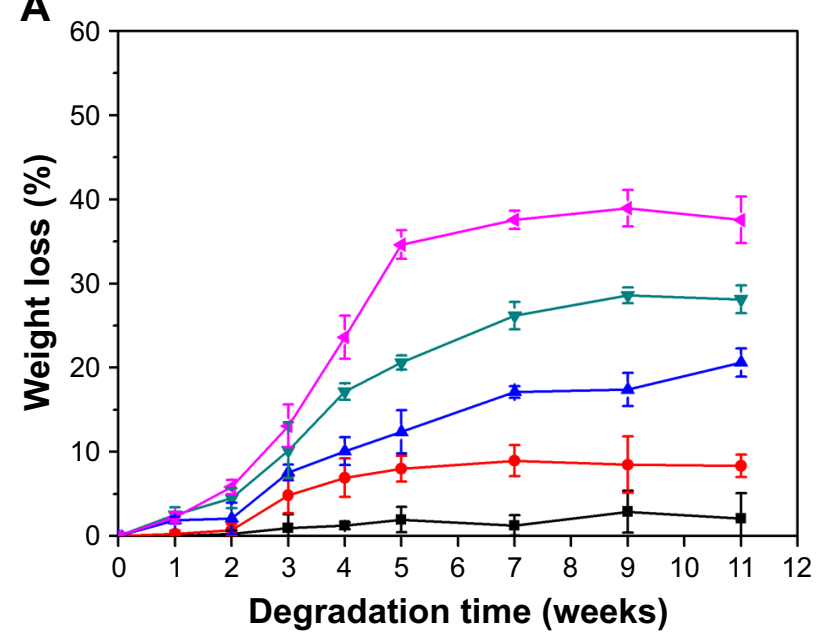

B

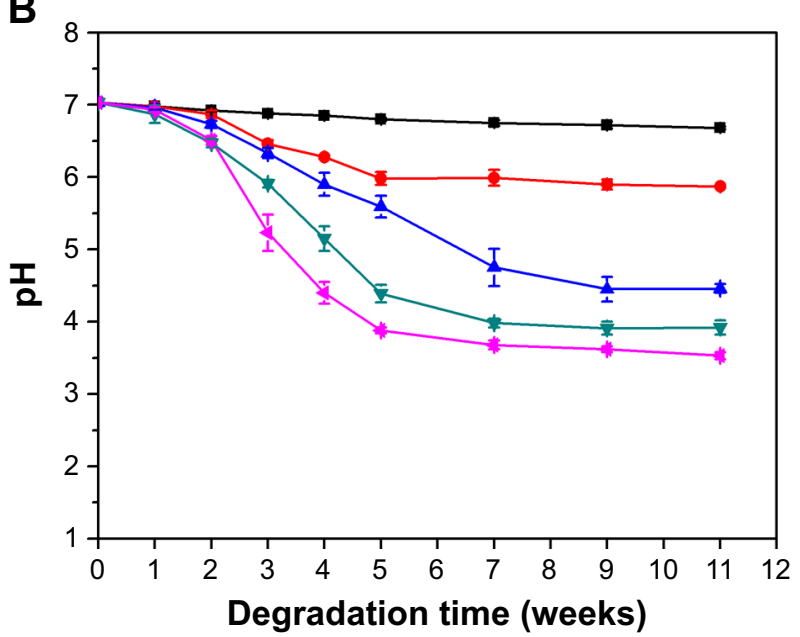

properties of samples. In contrast with PLLA/PCL scaffold, the compressive strength and modulus of PLLA/PLGA/ PCL scaffold significantly decrease to $0.067 \pm 0.006$ and $0.98 \pm 0.19 \mathrm{MPa}$, respectively (Figure $8 \mathrm{~B}$ and C). However, degradation in vitro for 5 weeks has no obvious effect on the compressive properties of the cylindrical PLLA/PLGA/ PCL scaffold.

The results of tensile and compressive tests indicate that the mechanical properties of PLLA/PLGA/PCL scaffold are lower than those of PLLA/PCL scaffold. It may be due to that PLLA/PLGA/PCL scaffold possesses larger macropore size and better pore interconnectivity. Moreover, degradation in vitro for 5 weeks significantly reduces the tensile properties of PLLA/PLGA/PCL scaffold but has no obvious effect on the compressive properties. Also, the suture strength of PLLA/PLGA/PCL 30:40:30 vascular scaffold was measured to be $0.27 \pm 0.02 \mathrm{~N}$, which is obviously less than those of human mammary artery $(1.40 \pm 0.01 \mathrm{~N})$ and human saphenous vein $(1.81 \pm 0.02 \mathrm{~N}){ }^{22}$ Nonetheless, PLLA/PLGA/PCL 30:40:30 scaffold possesses the elastic modulus of $6.22 \pm 1.89 \mathrm{MPa}$ and the compressive modulus of $0.98 \pm 0.19 \mathrm{MPa}$ before degradation, endowing it with enough strength to withstand external forces.

\section{In vivo subcutaneous implantation}

In order to further verify that the macropores in the prepared PLLA/PLGA/PCL 30:40:30 scaffold are interconnected and large enough for cell infiltration, the scaffolds were implanted

$$
\begin{gathered}
\rightarrow \multimap \text { PLLA/PLGA/PCL 70:0:30 } \rightarrow \text { PLLA/PLGA/PCL 60:10:30 } \multimap \text { PLLA/PLGA/PCL 50:20:30 } \\
\rightarrow \text { PLLA/PLGA/PCL 40:30:30 } \leftarrow \text { PLLA/PLGA/PCL 30:40:30 }
\end{gathered}
$$

Figure 4 In vitro degradation behavior of scaffolds in PBS solution $\left(\mathrm{pH} \mathrm{7.03)}\right.$ at $37^{\circ} \mathrm{C}$.

Notes: (A) Weight loss. (B) $\mathrm{pH}$ variation of degradation solutions.

Abbreviations: PCL, poly(ع-caprolactone); PLGA, poly(lactic-co-glycolic acid); PLLA, poly(L-lactic acid). 

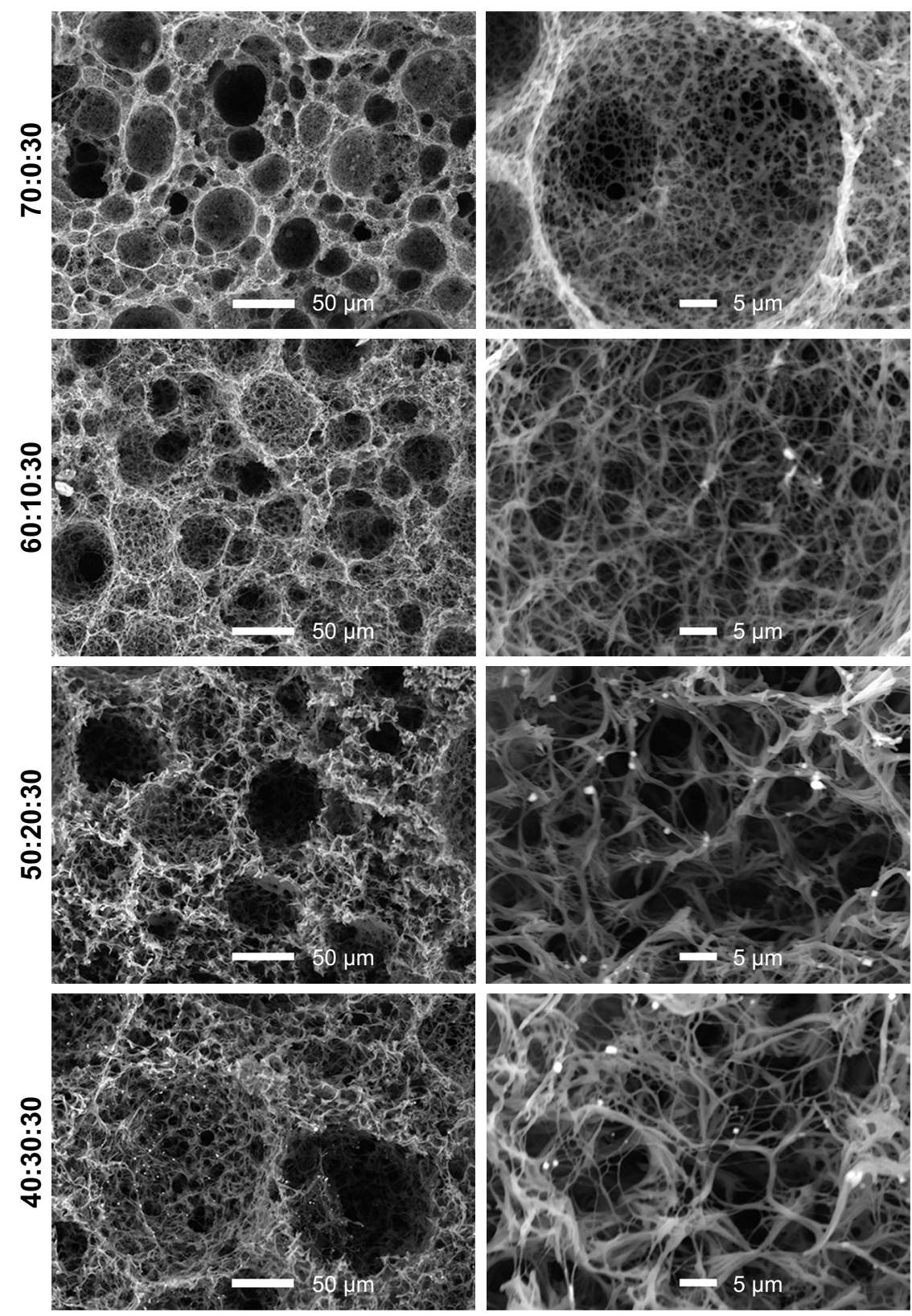

Figure 5 The SEM images of PLLA/PLGA/PCL composite scaffolds with the PLGA content from 0 to $30 \%$ after in vitro degradation for 8 weeks. Abbreviations: PCL, poly(ع-caprolactone); PLGA, poly(lactic-co-glycolic acid); PLLA, poly(L-lactic acid); SEM, scanning electron microscope.

subcutaneously into SD rats for $1,2,4$, and 8 weeks. The results shown in Figure 9 suggest that cells from rat body could infiltrate into the scaffold after implantation only for 1 week. With the increase in implantation time, cells infiltrate gradually into the scaffold by the form of cell coacervates. After implantation for 8 weeks, cells were resided into the whole scaffold with high cell density. In addition, collagen was produced in the scaffold by the infiltrated cells, which was evaluated visually by the Masson's trichrome staining. In contrast with the subcutaneous implantation results for PLLA/PCL scaffold reported in our previous study, ${ }^{9}$ cells infiltrate more easily into this PLLA/PLGA/PCL scaffold. These results indicate that PLLA/PLGA/PCL scaffold has better pore interconnectivity than PLLA/PCL scaffold, and the macropores are large enough for cells' infiltration, which is critical for the regeneration of functional neotissues. ${ }^{3}$

\section{Culture of HVSMCs}

In vascular tissue engineering, regeneration of tunica media is critical for the functionalization of neo-vessels, which usually requires porous scaffold for SMCs growth and infiltration. 

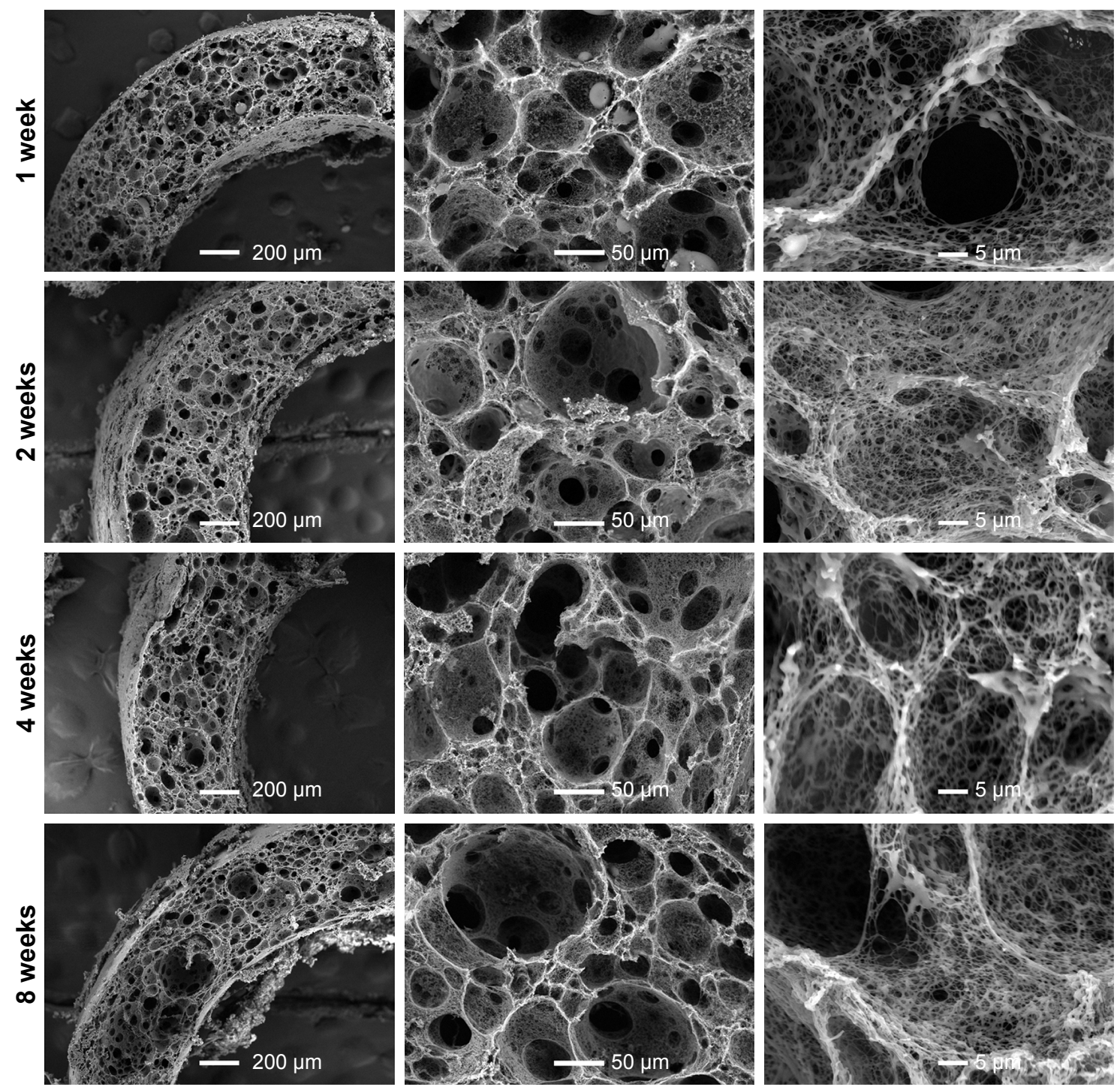

Figure 6 The SEM images of PLLA/PLGA/PCL 30:40:30 composite scaffolds after degradation in vitro for I, 2, 4, and 8 weeks.

Abbreviations: PCL, poly(ع-caprolactone); PLGA, poly(lactic-co-glycolic acid); PLLA, poly(L-lactic acid); SEM, scanning electron microscope.

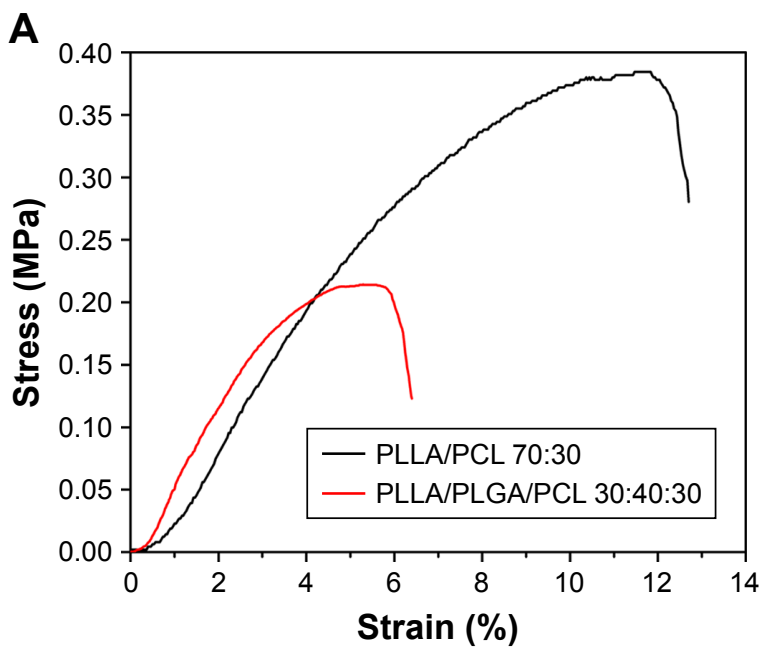

B

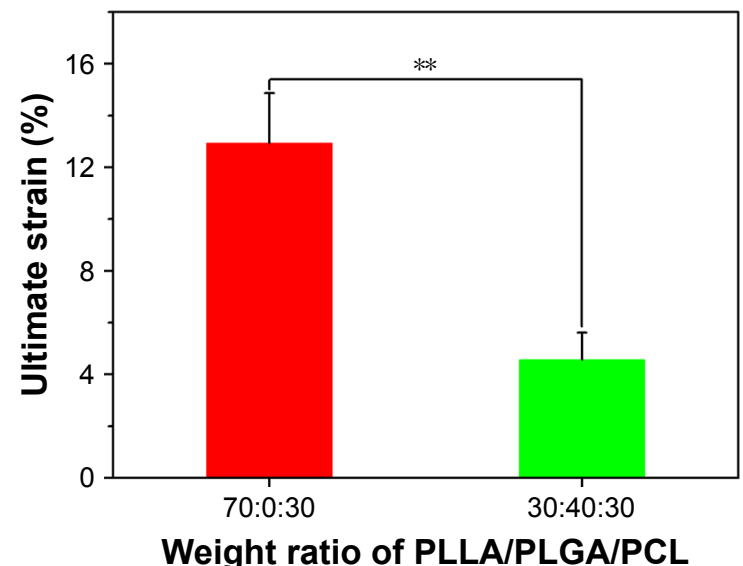

Figure 7 (Continued) 

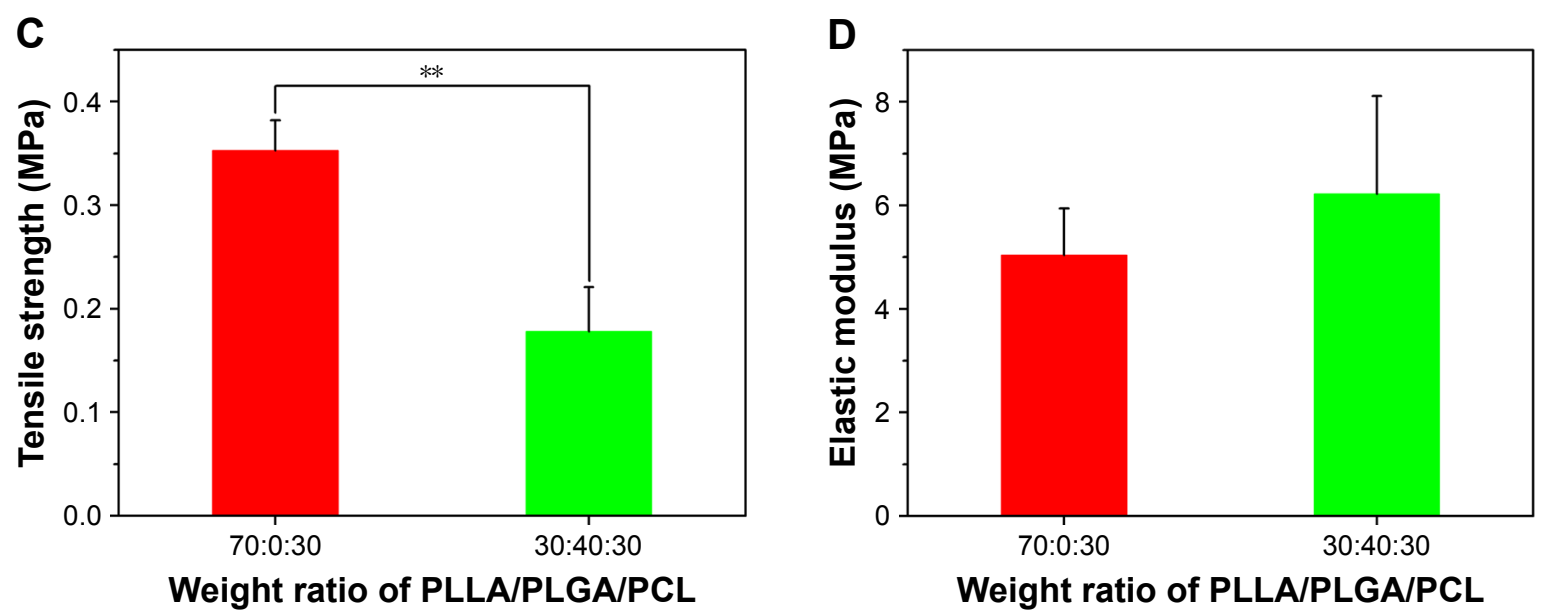

Figure 7 (A) Representative tensile stress-strain curves of scaffolds prepared from PLLA/PLGA/PCL blends with various blend ratios. (B) Ultimate strain, (C) tensile strength, and (D) elastic modulus of scaffolds prepared from PLLA/PLGA/PCL blends with various blend ratios.

Note: $* * P<0.01$.

Abbreviations: PCL, poly(E-caprolactone); PLGA, poly(lactic-co-glycolic acid); PLLA, poly(L-lactic acid).

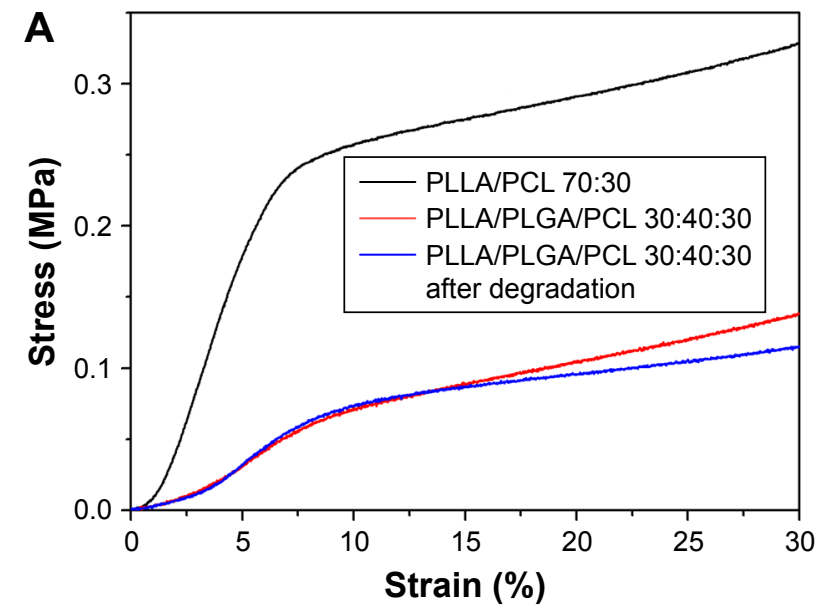

B

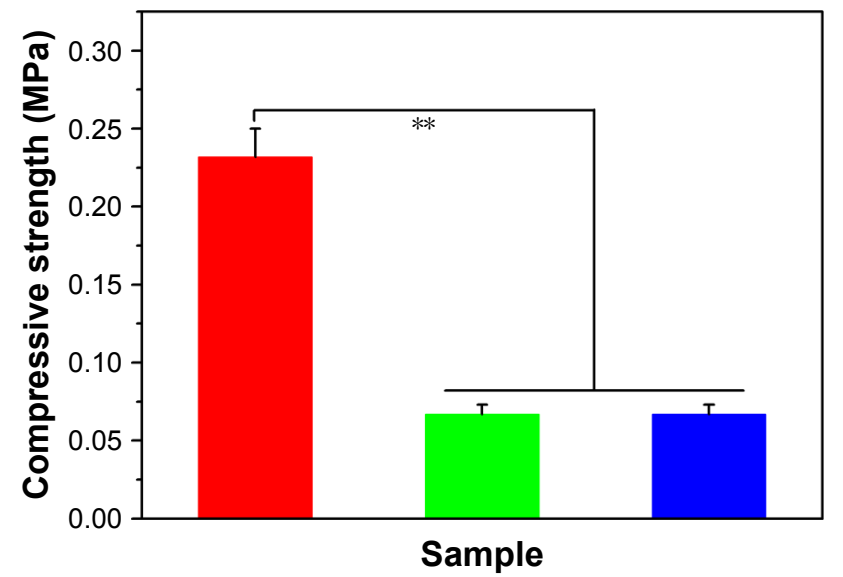

C

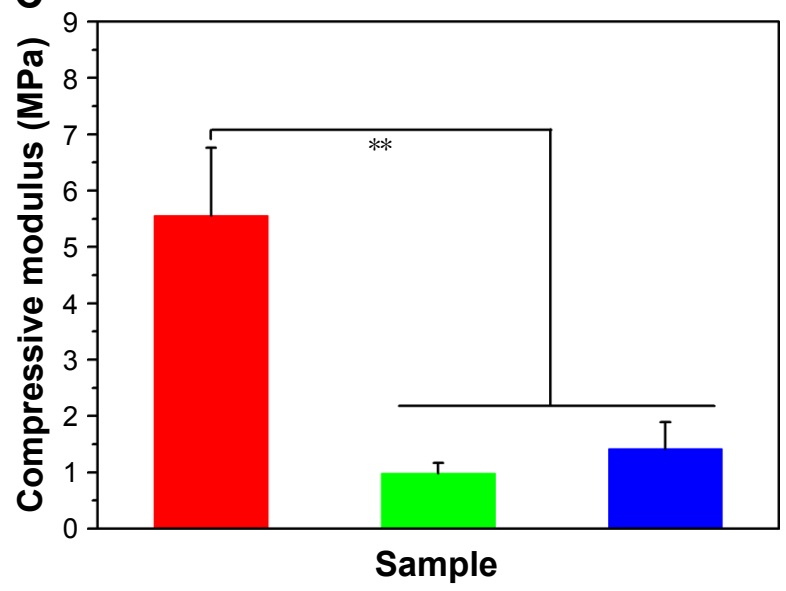

PLLA/PCL 70:30 PLLA/PLGA/PCL 30:40:30

PLLA/PLGA/PCL 30:40:30 after degradation

Figure 8 (A) The compressive stress-strain curves of PLLA/PCL 70:30 scaffold, PLLA/PLGA/PCL 30:40:30 scaffold, and the PLLA/PLGA/PCL 30:40:30 scaffold after degradation in vitro for 5 weeks. (B) Compressive strength and $(\mathbf{C})$ compressive modulus of the corresponding scaffolds.

Note: $* * P<0.01$.

Abbreviations: PCL, poly(E-caprolactone); PLGA, poly(lactic-co-glycolic acid); PLLA, poly(L-lactic acid). 

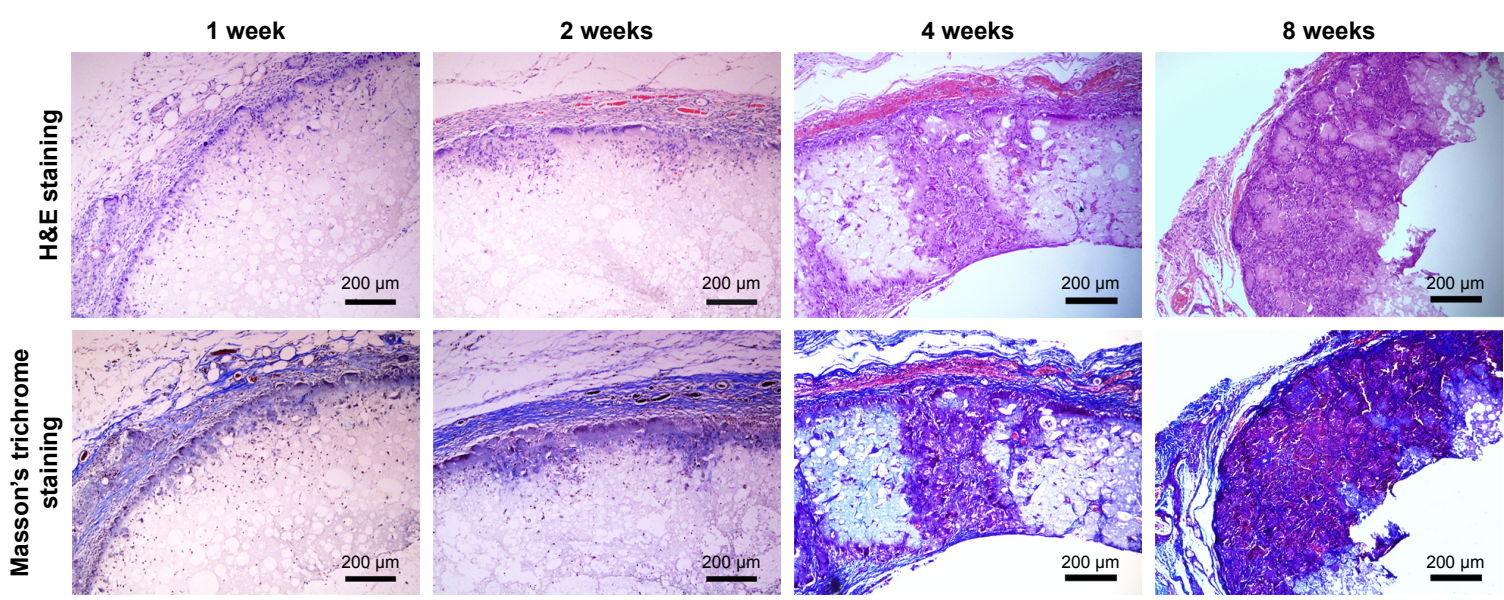

Figure 9 The histochemical analysis of PLLA/PLGA/PCL 30:40:30 scaffold after subcutaneous implantation in SD rat for I, 2, 4, and 8 weeks. Abbreviations: PCL, poly( $\varepsilon$-caprolactone); PLGA, poly(lactic-co-glycolic acid); PLLA, poly(L-lactic acid).

PLLA/PLGA/PCL scaffold has the potential to be a promising candidate for SMCs' growth and infiltration due to its macroporous structure with large pore size and excellent pore interconnectivity. In order to confirm that, HVSMCs were selected as the model cells and seeded on the PLLA/ PLGA/PCL scaffold.

Figure 10A shows HVSMCs' proliferation on PLLA/PCL and PLLA/PLGA/PCL scaffolds. Cells could grow on the
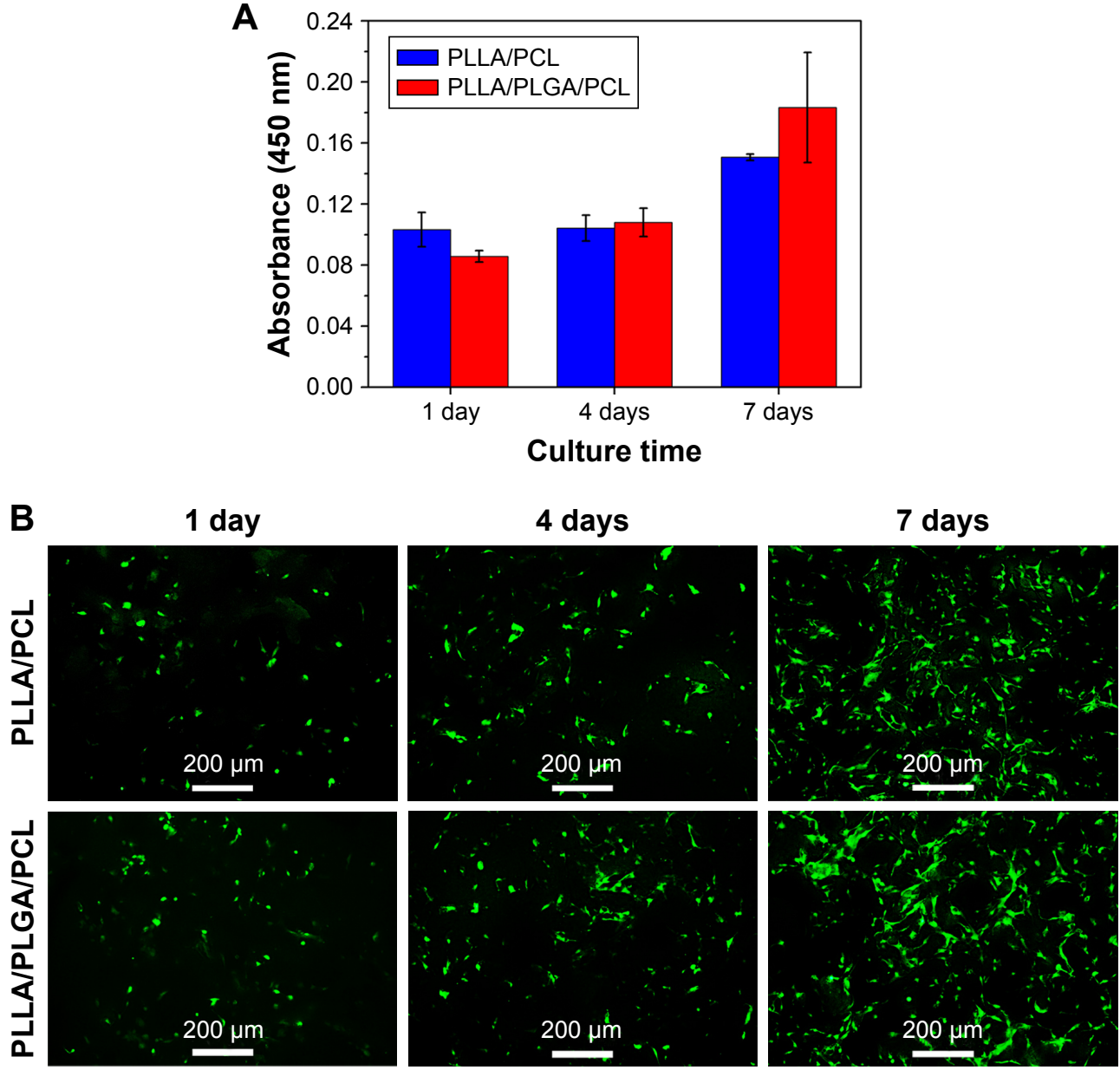

Figure 10 (A) CCK-8 assays of HVSMCs cultured on PLLA/PCL and PLLA/PLGA/PCL scaffold for I, 4, and 7 days. (B) Living cell staining of HVSMCs cultured on PLLA/PCL and PLLA/PLGA/PCL scaffold for different culture times by using Calcein-AM.

Abbreviations: CCK-8, cell counting kit-8; HVSMCs, human vascular smooth muscle cells; PCL, poly(E-caprolactone); PLGA, poly(lactic-co-glycolic acid); PLLA, poly(L-lactic acid). 
scaffold with the increase in culture time, but there is no significant difference in HVSMCs' adhesion and proliferation on PLLA/PCL and PLLA/PLGA/PCL scaffolds, indicating that the additional PLGA has no obvious effect on the cytocompatibility of composite scaffold, which is also reflected in the results of living cells staining of HVSMCs cultured on the scaffold. As shown in Figure 10B, HVSMCs attach on the scaffolds by the round shape after seeded for 1 day. After culturing for longer time, HVSMCs begin to spread on the scaffold surface and gradually proliferate with the increase in culture time. Moreover, after culturing for 7 days, HVSMCs infiltrate into the interior of PLLA/PLGA/PCL scaffold and express the marker protein, $\alpha$-SMA (Figure 11B and D), but rare HVSMCs infiltrate into the interior of PLLA/PCL scaffold (Figure 11A and C). These results again indicate the improved pore size and interconnectivity in PLLA/ PLGA/PCL scaffold and forebode that PLLA/PLGA/PCL scaffold would be promising in vascular tissue engineering applications for SMCs' infiltration and functional tunica media regeneration.

\section{Immobilization of PDGF-BB and enhanced bioactivities of HVSMCs}

Surface modification is an effective way to endow the tissue engineering scaffolds with improved biocompatibility while maintaining their bulk properties. In this study, heparin was selected as the surface modifier to be conjugated on the PLLA/PLGA/PCL scaffold, because it possesses strong binding affinity with various bioactive factors. ${ }^{30-32}$ The amount of heparin conjugated on the scaffold surface was measured to be $12.10 \pm 0.84 \mu \mathrm{g} / \mathrm{cm}^{2}$ by toluidine blue assay. ${ }^{19}$ Then, PDGF-BB was immobilized on the surface of heparinized scaffold via electrostatic interaction to enhance the interactions of SMCs with the nanofibrous scaffold. The amount of PDGF-BB immobilized on the scaffold was calculated to be $122.42 \pm 0.03 \mathrm{ng} / \mathrm{cm}^{2}$.

Figure 12 shows HVSMCs' proliferation on the modified scaffolds. As shown in Figure 12A, the absorbance for the untreated PLLA/PLGA/PCL scaffold gradually increases in this test, indicating that HVSMCs gradually proliferate on the untreated scaffold after culturing for 7 days, while the
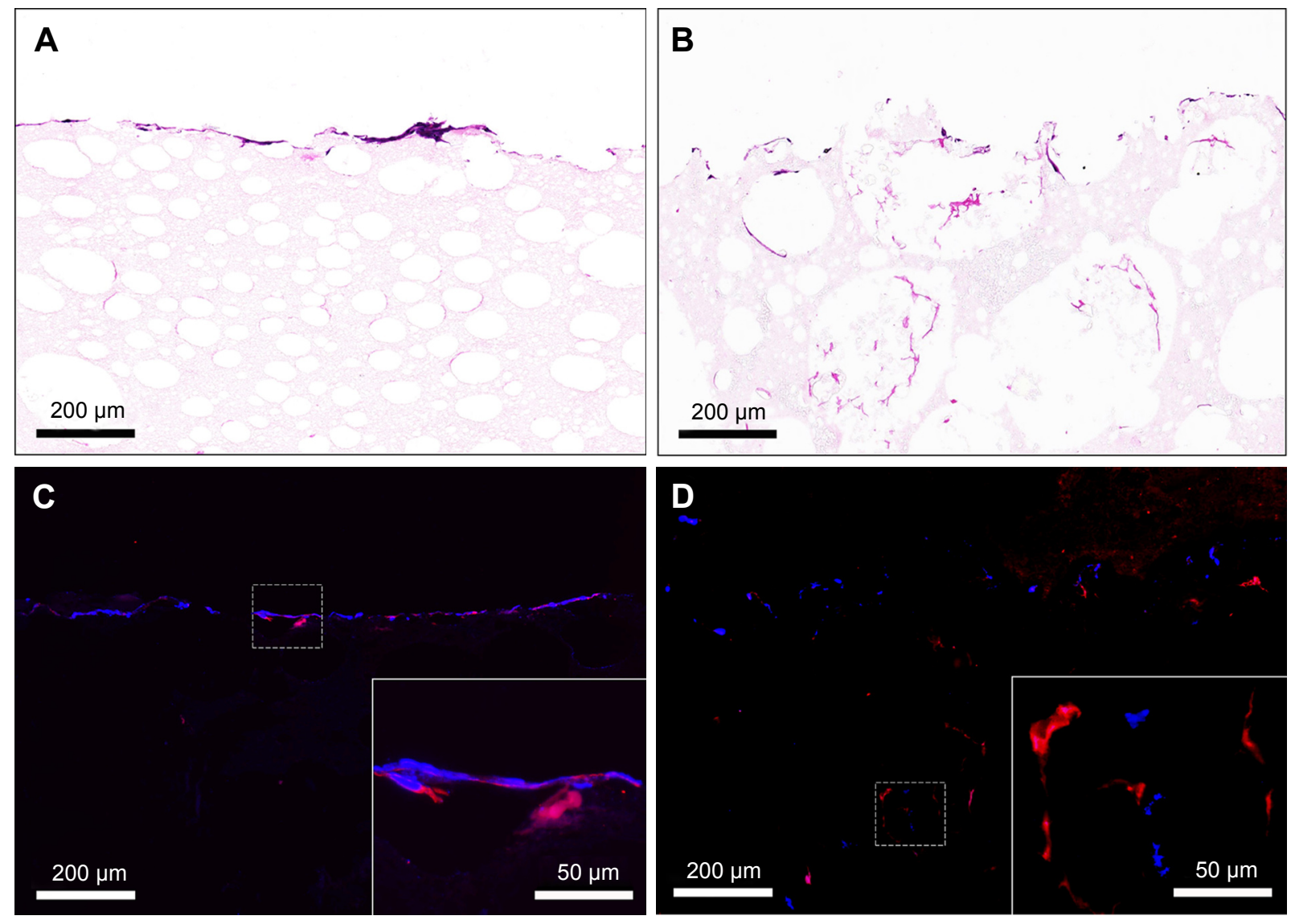

Figure II (A and $\mathbf{B})$ H\&E staining and (C and $\mathbf{D})$ immunofluorescence staining images for the cross-sections of $(\mathbf{A}$ and $\mathbf{C})$ PLLA/PCL and (B and $\mathbf{D})$ PLLA/PLGA/PCL scaffolds seeded with HVSMCs for 7 days.

Notes: Red indicates $\alpha$-SMA. Blue indicates cell nucleus.

Abbreviations: HVSMCs, human vascular smooth muscle cells; PCL, poly( $\varepsilon$-caprolactone); PLGA, poly(lactic-co-glycolic acid); PLLA, poly(L-lactic acid); $\alpha$-SMA, $\alpha$-smooth muscle actin. 


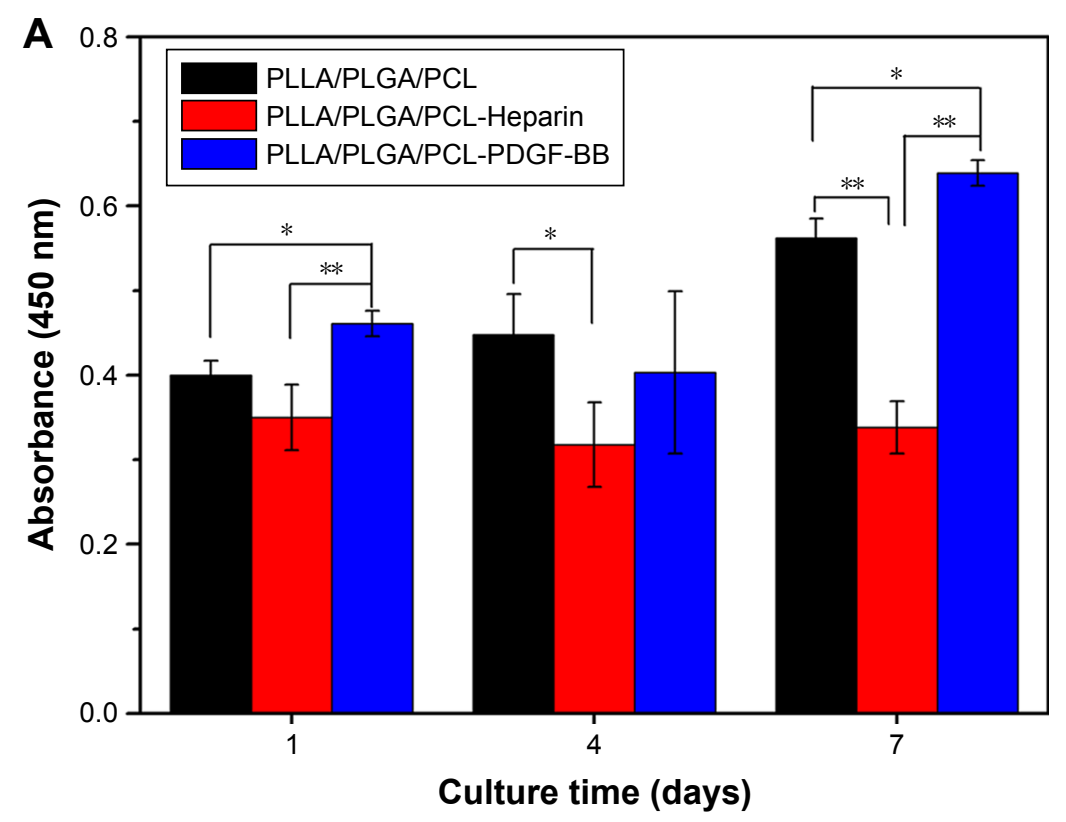

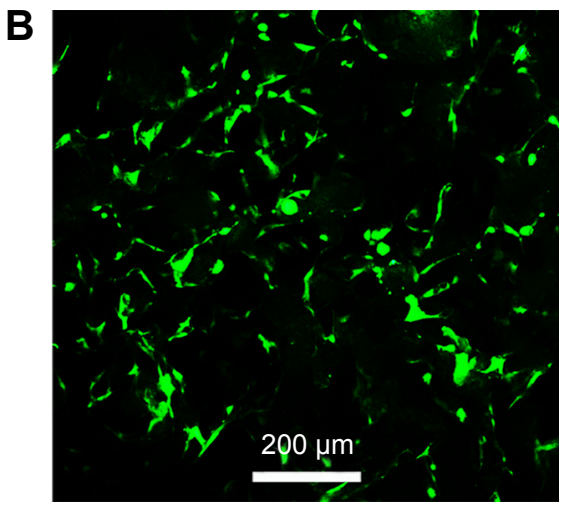

PLLA/PLGA/PCL

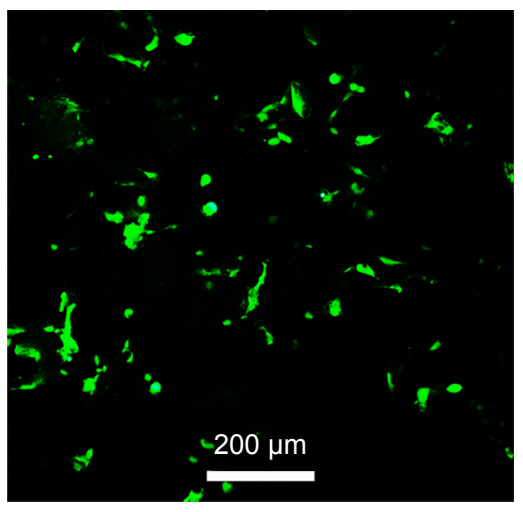

PLLA/PLGA/PCL-Heparin

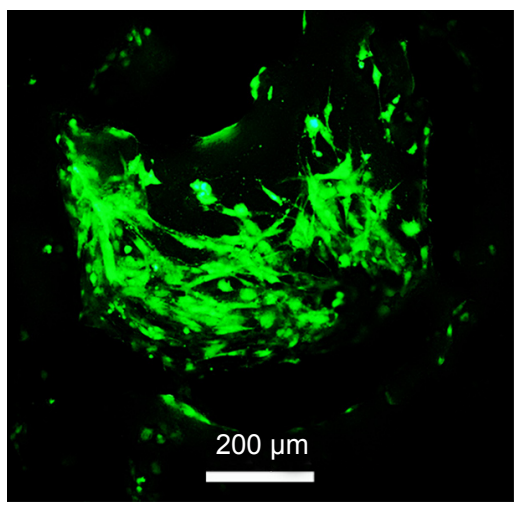

PLLA/PLGA/PCL-PDGF-BB

Figure 12 (A) CCK-8 assays of HVSMCs cultured on the PLLA/PLGA/PCL, PLLA/PLGA/PCL-Heparin, and PLLA/PLGA/PCL-PDGF-BB scaffolds for I, 4, and 7 days. (B) Living cell staining of HVSMCs cultured on the PLLA/PLGA/PCL, PLLA/PLGA/PCL-Heparin, and PLLA/PLGA/PCL-PDGF-BB scaffolds for 7 days by using Calcein-AM. Notes: $* P<0.05$. $* * P<0.01$.

Abbreviations: CCK-8, cell counting kit-8; HVSMCs, human vascular smooth muscle cells; PCL, poly(E-caprolactone); PDGF-BB, platelet-derived growth factor-BB; PLGA, poly(lactic-co-glycolic acid); PLLA, poly(L-lactic acid).

absorbance for the PLLA/PLGA/PCL-Heparin scaffold almost keeps constant and is obviously lower than that for the untreated scaffold after culturing for longer than 1 day, indicating that surface modification with heparin on the scaffold limits the proliferation of SMCs, which is in accordance with the previous work. ${ }^{33}$ However, significantly higher absorbance is measured for the PLLA/PLGA/PCL-PDGF-BB scaffold after culturing for 7 days than that for the untreated scaffold. It demonstrates that further immobilization with PDGF-BB on the heparinized scaffold eliminates the inhibiting effect of heparin on SMCs' proliferation and reversely facilitates the proliferation of SMCs on the scaffold. Meanwhile, the living cell staining of HVSMCs cultured on the three scaffolds for 7 days is shown in Figure 12B. As shown in the figure, more HVSMCs show the spread morphology on the PLLA/PLGA/PCL-PDGF-BB scaffold compared with that on other scaffolds, indicating that surface modification with PDGF-BB improves the interactions of SMCs with the nanofibrous scaffold.

Finally, the influence of surface modification on the migration of SMCs was studied using a Transwell system. As shown in Figure 13A-D, HVSMCs could migrate across the Transwell membrane and spread on the lower site of the membrane. No significantly difference of cell density on the lower site of Transwell membrane is observed between the untreated PLLA/PLGA/PCL scaffold and tissue culture plate (TCP) group (Figure 13A and B). However, the HVSMCs density for the PLLA/PLGA/PCL-Heparin 

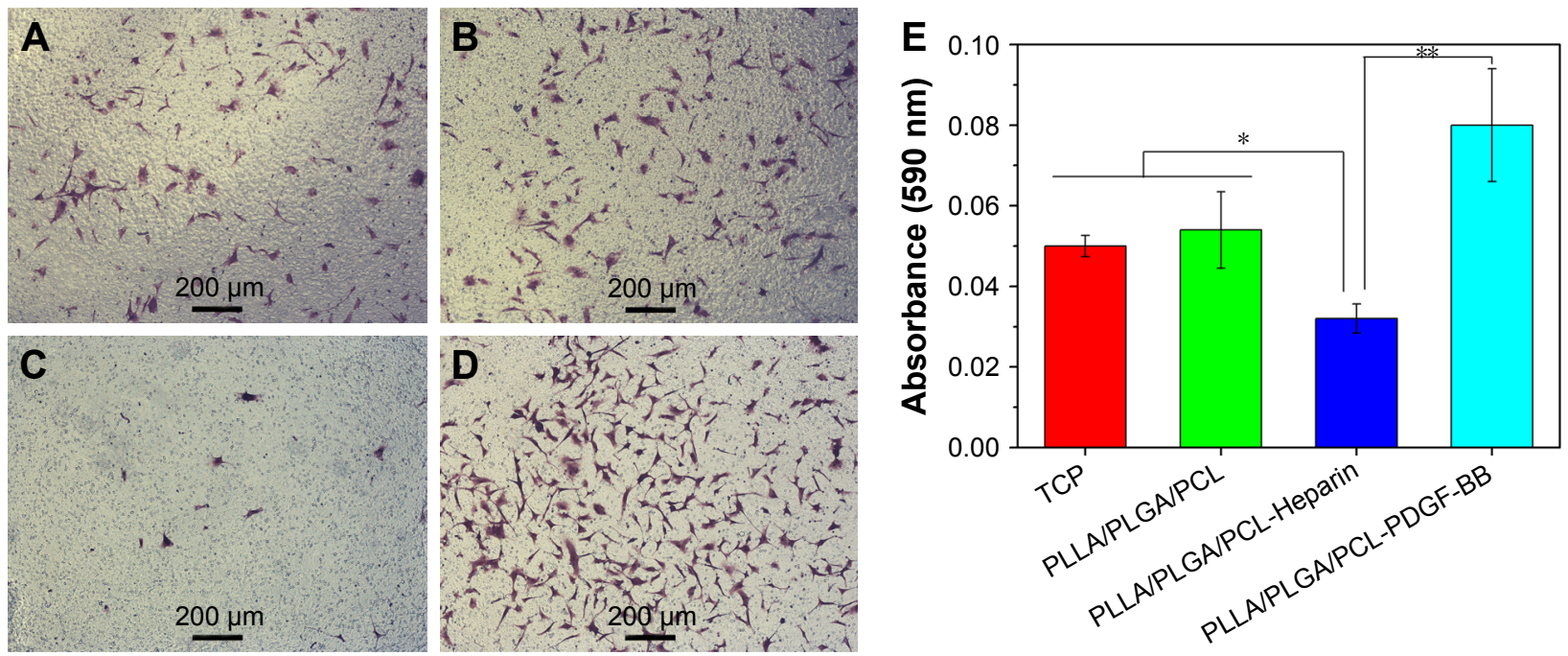

Figure 13 (A-D) The representative image of the migratory HVSMCs located on the lower site of Transwell membrane for the TCP, PLLA/PLGA/PCL, PLLA/PLGA/PCLHeparin, and PLLA/PLGA/PCL-PDGF-BB scaffolds, respectively. (E) The quantification of HVSMCs migration.

Notes: $* P<0.05$. $* * P<0.01$.

Abbreviations: HVSMCs, human vascular smooth muscle cells; PCL, poly(E-caprolactone); PDGF-BB, platelet-derived growth factor-BB; PLGA, poly(lactic-co-glycolic acid); PLLA, poly(L-lactic acid); TCP, tissue culture plate.

scaffold obviously decreases compared with that for the untreated scaffold (Figure 13C), meaning that the released heparin from the PLLA/PLGA/PCL-Heparin scaffold inhibits SMCs migration, which is also in accordance with the well-known conclusion that heparin is the potent inhibitor of SMCs' migration. ${ }^{34,35}$ Notably, more HVSMCs migrate to the lower site of membrane for the PLLA/PLGA/PCLPDGF-BB scaffold in comparison with the untreated scaffold (Figure 13D), indicating that further immobilization with PDGF-BB on the heparinized scaffold eliminates the negative effect of heparin on SMCs migration and further facilitates the migration of SMCs. These results are also confirmed by the quantitatively measure of the migratory cells as shown in Figure 13E.

\section{Conclusion}

In this study, dual phase separation technique was expanded using ternary polymer blend to fabricate macroporous and nanofibrous scaffold. The as-prepared PLLA/PLGA/PCL composite scaffold with the weight ratio of 30:40:30 possessed not only improved degradation property but also larger pore size and better pore interconnectivity due to the addition of PLGA into PLLA/PCL blend. It had enough mechanical properties to withstand external forces for tissue engineering applications. The highly porous structure of the scaffold enabled HVSMCs' infiltration and expression of $\alpha$-SMA. In addition, the nanofibrous scaffold can be surface modified with PDGF-BB to enhance the proliferation and migration of SMCs. These results indicated that this PLLA/PLGA/PCL scaffold would be a promising matrix for the infiltration of vascular SMCs and regeneration of functional tunica media in vascular tissue engineering application. Moreover, this study puts forward a strategy to expand dual phase separation technique into utilizing ternary even multinary polymer blend to fabricate macroporous nanofibrous scaffold with improved physicochemical properties.

\section{Acknowledgments}

This work was financially supported by the National Natural Science Foundation of China (31570984 and 31771048), National Key Research and Development Program of China (2018YFB1105602), International Cooperation Fund of the Science and Technology Commission of Shanghai Municipality (15540723400), Fundamental Research Funds for the Central Universities (2232018A3-07), and Chinese Universities Scientific Fund (CUSF-DH-D-2016030).

\section{Disclosure}

The authors report no conflicts of interest in this work.

\section{References}

1. Ma PX. Biomimetic materials for tissue engineering. Adv Drug Delivery Rev. 2008;60:184-198.

2. Holzwarth JM, Ma PX. 3D nanofibrous scaffolds for tissue engineering. J Mater Chem. 2011;21(28):10243-10251.

3. Wei G, Ma PX. Macroporous and nanofibrous polymer scaffolds and polymer/bone-like apatite composite scaffolds generated by sugar spheres. J Biomed Mater Res A. 2006;78(2):306-315.

4. Ribeiro VP, da Silva Morais A, Maia FR, et al. Combinatory approach for developing silk fibroin scaffolds for cartilage regeneration. Acta Biomater. 2018;72:167-181. 
5. Wang Z, Cui Y, Wang J, et al. The effect of thick fibers and large pores of electrospun poly( $\varepsilon$-caprolactone) vascular grafts on macrophage polarization and arterial regeneration. Biomaterials. 2014;35(22): 5700-5710.

6. Woo KM, Chen VJ, Ma PX. Nano-fibrous scaffolding architecture selectively enhances protein adsorption contributing to cell attachment. J Biomed Mater Res A. 2003;67(2):531-537.

7. Wei G, Ma PX. Nanostructured Biomaterials for Regeneration. Adv Funct Mater. 2008;18(22):3568-3582.

8. He C, Nie W, Feng W. Engineering of biomimetic nanofibrous matrices for drug delivery and tissue engineering. J Mater Chem B. 2014;2: $7828-7848$

9. Wang W, Nie W, Zhou X, et al. Fabrication of heterogeneous porous bilayered nanofibrous vascular grafts by two-step phase separation technique. Acta Biomater. 2018;79:168-181.

10. Liu X, Ma PX. The nanofibrous architecture of poly(L-lactic acid)-based functional copolymers. Biomaterials. 2010;31(2):259-269.

11. Zhao S, Zhao X, Dong S, et al. A hierarchical, stretchable and stiff fibrous biotemplate engineered using stagger-electrospinning for augmentation of rotator cuff tendon-healing. J Mater Chem B. 2015;3(6): 990-1000.

12. van Dijk M, Tunc DC, Smit TH, Higham P, Burger EH, Wuisman PI. In vitro and in vivo degradation of bioabsorbable PLLA spinal fusion cages. J Biomed Mater Res. 2002;63(6):752-759.

13. Castilla-Cortázar I, Más-Estellés J, Meseguer-Dueñas JM, Escobar Ivirico JL, Marí B, Vidaurre A. Hydrolytic and enzymatic degradation of a poly(E-caprolactone) network. Polym Degrad Stab. 2012;97(8): 1241-1248.

14. Wu W, Allen RA, Wang Y. Fast-degrading elastomer enables rapid remodeling of a cell-free synthetic graft into a neoartery. Nat Med. 2012; 18(7):1148-1153.

15. Lai Y, Cao H, Wang X, et al. Porous composite scaffold incorporating osteogenic phytomolecule icariin for promoting skeletal regeneration in challenging osteonecrotic bone in rabbits. Biomaterials. 2018;153: $1-13$.

16. Wang W, Miao Y, Zhou X, et al. Local delivery of BMP-2 from poly(lactic-co-glycolic acid) microspheres incorporated into porous nanofibrous scaffold for bone tissue regeneration. J Biomed Nanotechnol. 2017;13(11):1446-1456.

17. Yoshioka T, Kamada F, Kawazoe N, Tateishi T, Chen G. Structural changes and biodegradation of PLLA, PCL, and PLGA sponges during in vitro incubation. Polym Eng Sci. 2010;50(10):1895-1903.

18. Tsuji H, Yamada T. Blends of aliphatic polyesters. VIII. Effects of poly(L-lactide-co- $\varepsilon$-caprolactone) on enzymatic hydrolysis of poly(Llactide), poly( $\varepsilon$-caprolactone), and their blend films. J Appl Polym Sci. 2003;87(3):412-419.

19. Wang W, Hu J, He C, et al. Heparinized PLLA/PLCL nanofibrous scaffold for potential engineering of small-diameter blood vessel: tunable elasticity and anticoagulation property. J Biomed Mater Res A. 2015; 103(5):1784-1797.
20. Perros F, Montani D, Dorfmüller P, et al. Platelet-derived growth factor expression and function in idiopathic pulmonary arterial hypertension. Am J Respir Crit Care Med. 2008;178(1):81-88.

21. Jia Y, Wang W, Zhou X, Nie W, Chen L, He C. Synthesis and characterization of poly(glycerol sebacate)-based elastomeric copolyesters for tissue engineering applications. Polym Chem. 2016;7(14):2553-2564.

22. Han F, Jia X, Dai D, et al. Performance of a multilayered small-diameter vascular scaffold dual-loaded with VEGF and PDGF. Biomaterials. 2013; 34(30):7302-7313.

23. Yu J, Wang A, Tang Z, et al. The effect of stromal cell-derived factor- $1 \alpha /$ heparin coating of biodegradable vascular grafts on the recruitment of both endothelial and smooth muscle progenitor cells for accelerated regeneration. Biomaterials. 2012;33(32):8062-8074.

24. Zieris A, Chwalek K, Prokoph S, et al. Dual independent delivery of pro-angiogenic growth factors from starPEG-heparin hydrogels. J Control Release. 2011;156(1):28-36.

25. Dobry A, Boyer-Kawenoki F. Phase separation in polymer solution. J Polym Sci Part A: Polym Chem. 1947;2:90-100.

26. Zhang Y, Ouyang H, Lim CT, Ramakrishna S, Huang ZM. Electrospinning of gelatin fibers and gelatin/PCL composite fibrous scaffolds. J Biomed Mater Res B Appl Biomater. 2005;72(1):156-165.

27. Elsdale T, Bard J. Collagen substrata for studies on cell behavior. J Cell Biol. 1972;54(3):626-637.

28. Li X, Feng Q, Wang W, Cui F. Chemical characteristics and cytocompatibility of collagen-based scaffold reinforced by chitin fibers for bone tissue engineering. J Biomed Mater Res B Appl Biomater. 2006;77(2): 219-226.

29. Barnes CP, Sell SA, Boland ED, Simpson DG, Bowlin GL. Nanofiber technology: designing the next generation of tissue engineering scaffolds. Adv Drug Deliv Rev. 2007;59(14):1413-1433.

30. Younesi M, Knapik DM, Cumsky J, et al. Effects of PDGF-BB delivery from heparinized collagen sutures on the healing of lacerated chicken flexor tendon in vivo. Acta Biomater. 2017;63:200-209.

31. Hettiaratchi MH, Rouse T, Chou C, et al. Enhanced in vivo retention of low dose BMP-2 via heparin microparticle delivery does not accelerate bone healing in a critically sized femoral defect. Acta Biomater. 2017; 59:21-32.

32. Awada HK, Long DW, Wang Z, Hwang MP, Kim K, Wang Y. A single injection of protein-loaded coacervate-gel significantly improves cardiac function post infarction. Biomaterials. 2017;125:65-80.

33. Clowes AW, Karnowsky MJ. Suppression by heparin of smooth muscle cell proliferation in injured arteries. Nature. 1977;265(5595): 625-626.

34. Majack RA, Clowes AW. Inhibition of vascular smooth muscle cell migration by heparin-like glycosaminoglycans. J Cell Physiol. 1984; $118(3): 253-256$.

35. Gu Z, Rolfe BE, Xu ZP, Thomas AC, Campbell JH, Lu GQ. Enhanced effects of low molecular weight heparin intercalated with layered double hydroxide nanoparticles on rat vascular smooth muscle cells. Biomaterials. 2010;31(20):5455-5462.
International Journal of Nanomedicine

\section{Publish your work in this journal}

The International Journal of Nanomedicine is an international, peerreviewed journal focusing on the application of nanotechnology in diagnostics, therapeutics, and drug delivery systems throughout the biomedical field. This journal is indexed on PubMed Central, MedLine, CAS, SciSearch ${ }^{\circledR}$, Current Contents ${ }^{\circledR} /$ Clinical Medicine,
Dovepress

Journal Citation Reports/Science Edition, EMBase, Scopus and the Elsevier Bibliographic databases. The manuscript management system is completely online and includes a very quick and fair peer-review system, which is all easy to use. Visit http://www.dovepress.com/ testimonials.php to read real quotes from published authors. 